\title{
Turmeric curcuminoid polyphenolics as antioxidant and anticarcinogenic agents
}

\author{
Ozlem Tokusoglu $^{1 *}$, Alkan Simsek $^{2}$, Murtaza Parvizi $^{3}$, Dilvin Eymen $^{1}$
}

\begin{abstract}
In this review content, it has been described the botanical and the chemical properties of turmeric (Curcuma longa), and its curcuminoid polyphenolic structures and antioxidant and anticarcinogenic influences on various cell proliferation and apoptosis. Besides it was emphasized the innovative anticarcinogen complex as boroncurcumin, and the safety evaluation with turmeric curcumin and the dose and toxicity in consuming for animals and human.
\end{abstract}

Keywords: Turmeric, Curcuma longa, Antioxidant, Anticarcinogenic.

\section{Introduction}

Turmeric (Curcuma longa) is extensively consumed as a spice, food preservative, colouring food and agent and it is cultivated in India, South East Asia and China and other countries (Figure 1). Turmeric is a medicinal plant extensively used in Ayurveda, Unani and Siddha medicine as home remedy for various diseases (1). Dried turmeric powder is also utilized in sub-continental cooking and is the main ingredient in all forms of "curry" preparations. The wild turmeric is called C. aromatica and the domestic species is called C. longa. Turmeric has been described as C. longa by Linnaeus and its taxonomic profile is as follows (1)

$\begin{array}{ll}\text { Class } & \text { Liliopsida } \\ \text { Subclass } & \text { Commelinids } \\ \text { Order } & \text { Zingiberales } \\ \text { Family } & \text { Zingiberaceae } \\ \text { Genus } & \text { Curcuma } \\ \text { Species } & \text { Curcuma longa }\end{array}$

Curcuma longa, a perennial herb and member of the Zingiberaceae (ginger) family, grows to a height of 35 feet with a tropical climate. It has oblong, pointed leaves and funnel-shaped yellow flowers (2) (Figure 1). Dried turmeric plant is the source of the spice, the ingredient that gives curry powder and has characteristic yellow-orange color (Figure 1).

It has stated that turmeric spice is an antioxidant, anticarcinogenic and has hepatoprotective, antiinflammatory, and antimicrobial properties. Besides, its utilizing in cardiovascular disease and gastrointestinal disorders. Current review has focused on turmeric's phenolic antioxidants as anticarcinogen agents
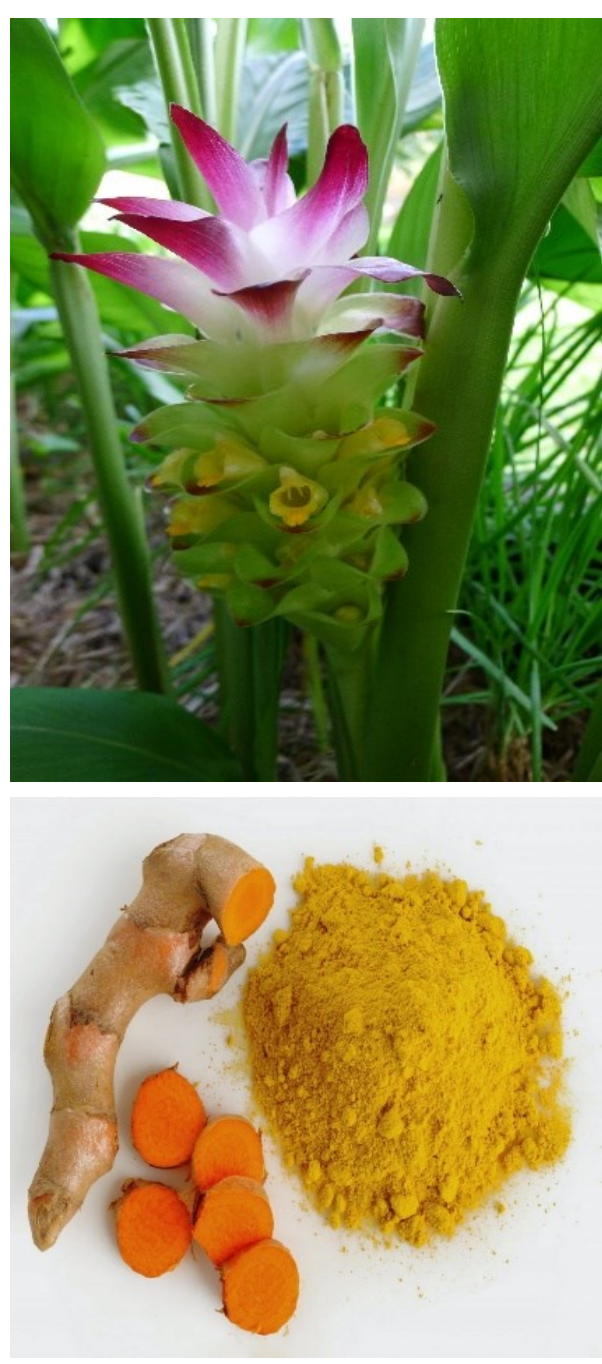

Figure 1: Turmeric (Curcuma longa) plant (left) and turmeric root and powder (right) (Anonim,2019) 


\section{Bioactive Constituents of Turmeric and Main Component Curcumin}

Turmeric spice includes $6.3 \%$ of total protein, $5.1 \%$ of total fat, $69.4 \%$ of carbohydrate and $13.1 \%$ of moisture. The main bioactive component of turmeric is curcumin (diferuloylmethane) as $3-4 \%$ and remain is essential oils including $\alpha$-phellandrene $(1 \%)$, sabinene $(0.6 \%)$, cineol $(1 \%)$, borneol $(0.5 \%)$, zingiberene $(25 \%)$ and sesquiterpines $(53 \%)$ in the structure (3). Curcumin is responsible for the yellow color and comprises three derivative containing curcumin I (94\%), curcumin II $(6 \%)$, and curcumin (III) $(0.3 \%)(3)$. the melting point of curcumin is 176 $177{ }^{\circ} \mathrm{C}$ and turns to reddish-brown salt with alkali agents. Turmeric is soluble in ethanol, acetic acid, ketone and chloroform. Figure 2 shows the chemical composition of curcumin and its keto-enol structure $(3,4)$.

Curcumin can exist in at least two tautomeric forms, keto and enol. It is stated that the enol form is more energetically stable in the solid phase and in solution (Figure 2).

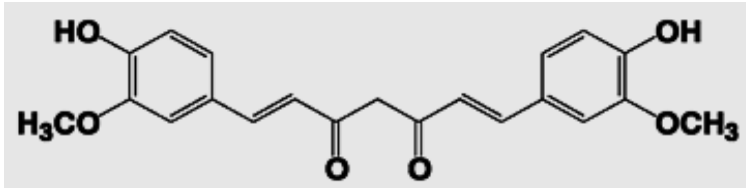

Keto form of Curcumin

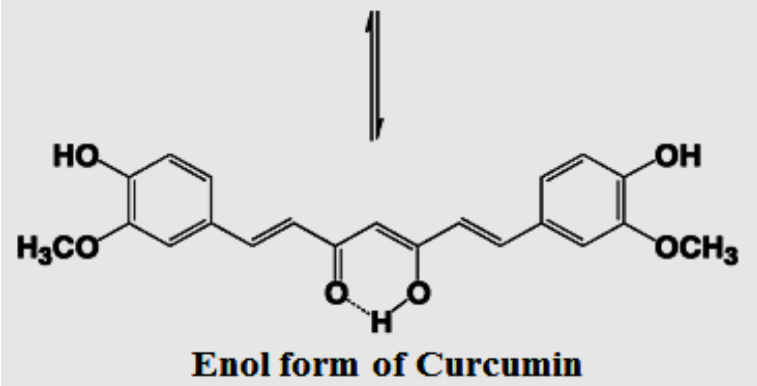

Figure 2. The Chemical Structure of Curcumin (4)

The chemical structures of curcumin derivatives as curcumin I, curcumin II demethoxycurcumin, and curcumin III bis-demethhoxycurcumin are given in Figure 3. Curcumin is the principal curcuminoid of spice turmeric, is a member of the ginger family (Zingiberaceae) and the other two curcuminoids are desmethoxycurcumin and bis-desmethoxycurcumin (Figure 3).

The curcuminoids are polyphenols and are responsible for the yellow-orange color of turmeric. Turmeric powder is yellow pigmented and has numerous curcuminoids that include curcumin (77\%), demethoxycurcumin $\quad(17 \%), \quad$ and bisdemethoxycurcumin (3\%). Curcumin is a polyphenol (1,7-bis(4-hydroxy-3-methoxyphenyl)1,6- heptadiene-3,5-dione).

Journal of Food Health and Technology Innovations June Vol 2, No 4 (2019)
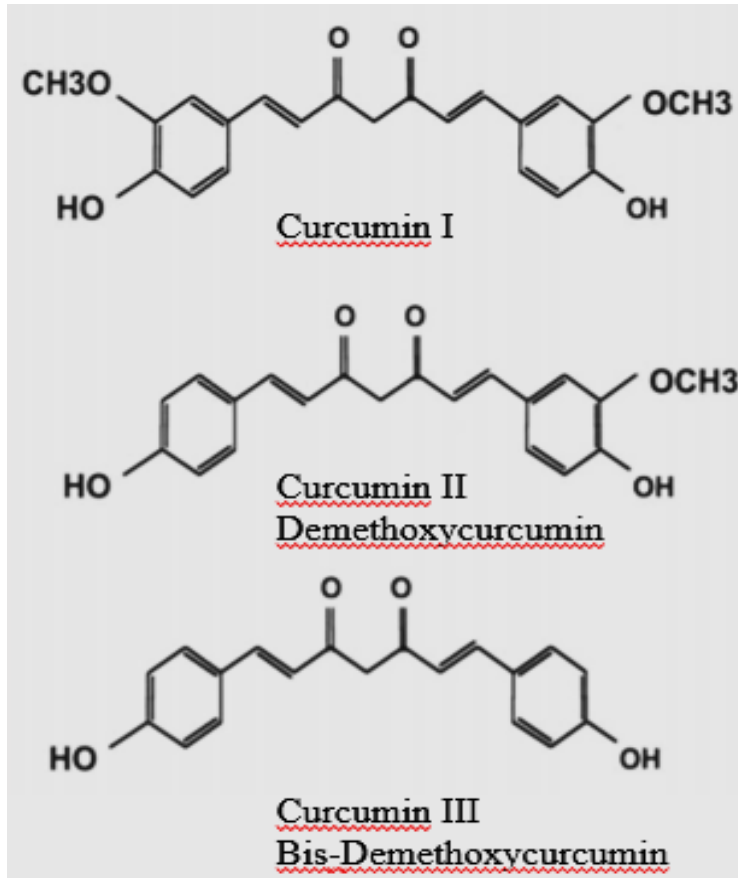

Figure 3. Curcumin Derivatives in Turmeric (5) Health Effects of Curcumin

Curcumin is brightly yellow coloured and may be used as a food colouring. As a food additive, its E number is E100. In ayurvedic medicine, it has been used for various disorders including asthma, bronchial hyperactivity, coryza, cough, sinusitis, allergy, anorexia, and hepatic diseases (6).

It has been reported that many positive health on antiinfectious (7), anti-oxidant (8), anti-inflammatory $(9,10)$, hepatoprotective $(11)$, cardio protective $(12)$, thrombosuppressive (13), anti-arthritic symptoms (14). It has been reported that curcumin suppresses the type II diabetes symptoms, reduces blood cholesterol, prevents LDL oxidation, inhibits platelet aggregation, suppresses thrombosis and myocardial infarction, supresses rheumatoid arthritis and multiple sclerosis symptoms and Alzheimer (15). It has been most importantly determined that curcumin has chemo preventive, and anti-carcinogenic properties (16).

\section{Antioxidant Effects of Curcumin}

Through a variety of assay systems in vitro and in vivo researches shown that curcumin and related compounds have great antioxidative activities. It is stated that, not only the phenolic hydroxyl (OH) groups of curcumin are most important in its antioxidative property but also the $\mathrm{OH}$ groups in the curcumin derivative bis (3,4-dihydroxycinnamoyl)methane and also possible role of $\beta$-diketone moiety in the curcumin structure (17-24). According to studies, the presence of an ortho alkoxy group seems to potentiate the antioxidant activity, as does an additional hydroxy group as in bis (3,4dihdroxy)cinnamoyl methane (24). It is reported that water-soluble and fat-soluble extracts of turmeric and its curcumin component exhibit strong antioxidant activity, comparable to ascorbic acid (vitamin C) (25). 


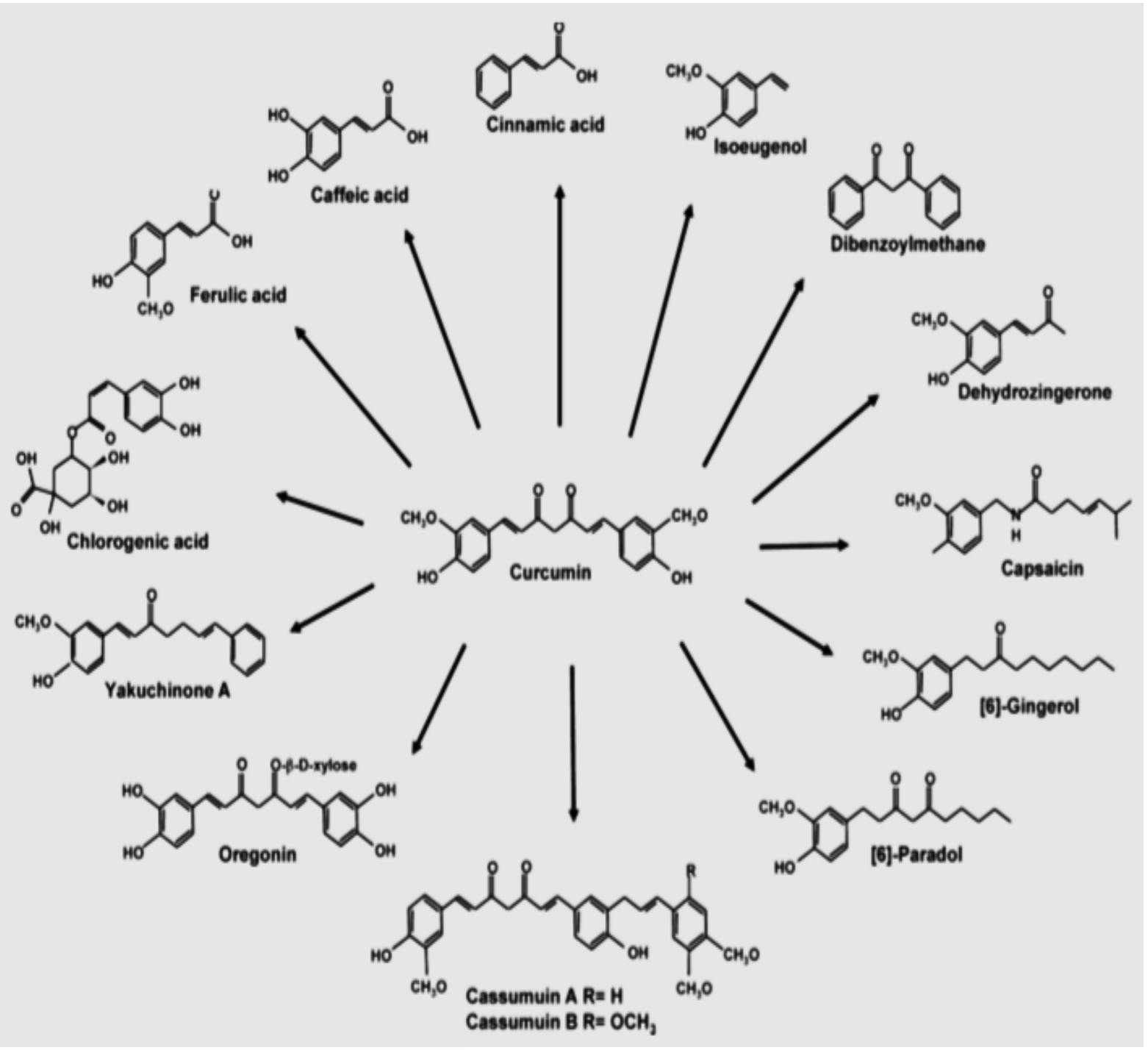

Figure 3. Curcumin analogues from mother structure (19)

Figure 3 shows a number of naturally occurring bioactive compounds having some structural similarity to the curcumin molecule, or at least having a pharmacophore including one aryl function with 3,4 substitution, either a methoxylated phenol or catechol (Figure 3). These compounds include ferulic acid, cinnamic acid, caffeic acid, chlorogenic acid, capsaicin, gingerol, paradol, zingerone, eugenols) or in two aromatic rings (e.g., oregonin, nitric oide synthase--iNOS inhibitör, dehydroguairetic acid, yakuchinones, cassumunins). The same chromophore is responsible for both the antioxidant and prooxidant properties of curcumin and its analogues that may be owing to the its radical-generating or hydrogen bond donor-acceptor properties.

\section{Anticarcinogenic effects of curcumin}

The extensive studies suggested that curcumin has the great potential in the prevention and treatment of cancer. In vitro and in vivo preclinical and clinical studies shown that curcumin has positive effects in the cancer treatment (15)

Journal of Food Health and Technology Innovations June Vol 2, No 4 (2019)
Curcumin has been shown to promote apoptosis in certain cancer cell lines and to inhibit telomerase activity, an important factor in tumorigenesis. One possible mechanism for the induction of tumor cell death is through the generation of reactive oxygen intermediates.

The oleoresin of turmeric which obtained after the extraction of curcumin has antimutagenic properties, thought to be mediated through its antioxidant action (16). In this chemopreventive effect, the anti-inflammatory properties of curcumin are also important and it is stated due the suppression of prostaglandin synthesis.

Curcumin polyphenolic substance has antiproliferative effects (5). It is reported that curcumin suppresses the proliferation of a wide variety of cancer tumor cells containing breast carcinoma, colon carcinoma, renal cell carcinoma, hepatocellular carcinoma, $\mathrm{T}$ cell leukaemia, B cell lymphoma, melanoma and prostate carcinoma, acute myelogenous leukaemia, basal cell carcinoma (5). 


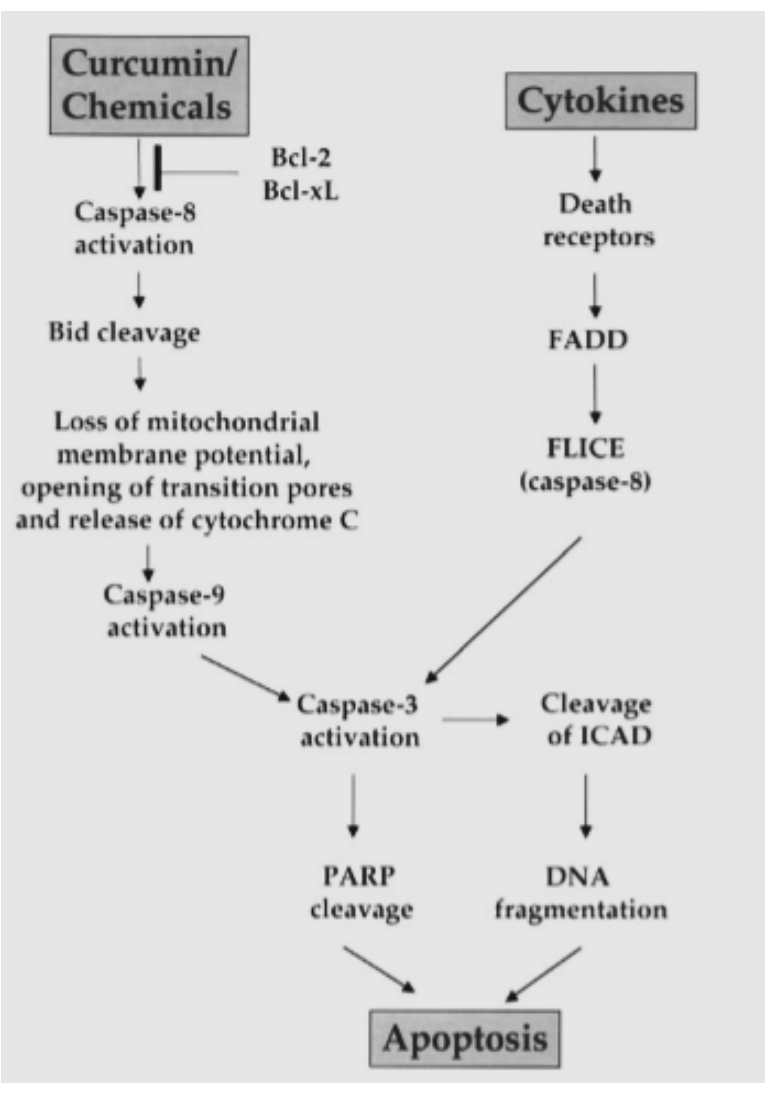

Figure 4. Curcumin Analogues from Mother Structure (5)

Besides, curcumin also inhibits the cell proliferation induced by growth factors such as IL-2-induced proliferation of PBMC, PDGF-induced proliferation of VSMC and PHA-induced proliferation of PBMC were inhibited by treatment with curcumin (26). It is stated that the suppression of cell proliferation by curcumin usually occurs through its effects on the cell cycle (27). Figure 4 shows the mechanism of apoptosis with curcumin. Moreover the suppression of proliferation, curcumin induces apoptosis in wide spectrum of cells. In this point, the apoptosis could be either mitochondria-dependent or mitochondriaindependent as shown in Figure 4. It is also reported that curcumin induces apoptotic cell death by DNAdamage in human cancer cell lines, TK-10, MCF-7 and UACC- 62 by acting as topoisomerase II poison (28).

\section{Boron-Curcumin Complex}

It is stated that curcumin can be used for boron quantification in the so-called curcumin method. It reacts with boric acid and gives a red coloured compound, known as rosocyanine (29). Rosocyanine is formed as 2:1 complex from curcumin and boric acid in acidic solutions. The boron complexes formed with rosocyanine are dioxaborines (1,3,2dioxaborine). Curcumin possesses a 1,3diketonestructure and can therefore be considered as a chelating agent.<smiles></smiles>

Figure 5. Curcumin-Boron Complex (Rosocyanine) (29)

It has been put forwarded that innovative synthetic strategies lead to soluble and crystallisable metal curcumin complexes (29). Also, it was described that the special emphasis is placed on the highly promising and exciting medicinal applications of metal curcumin complexes, with the three most important areas being anticancer activity and selective cytotoxicity, antiAlzheimer's disease activity, and antioxidative/neuroprotective effects (29).

\section{Safety evaluation with turmeric and curcumin}

Based on the detailed studies, it has been stated that the safety evaluation of the rhizomes of turmeric and its alcohol extract, curcumin was performed. However, the utilization of very high doses (100 $\mathrm{mg} / \mathrm{kg}$ body weight) resulted in ulcerogenic situation in animals, as evidenced by one rat study (30)

It has been reported that no pathological, behavioural abnormalities or lethality (31) and also no adverse effects were observed on growth and the level of erythrocytes, leucocytes, blood constituents such as haemoglobin, total serum protein, alkaline phosphatase, etc. in male and female Wistar rats, guinea pigs and monkeys of both sexes which were fed with turmeric at a dose of $300 \mathrm{mg} / \mathrm{kg}$ body weight (32).

Although various studies shown that no significant toxicity has been reported following either acute or chronic administration of turmeric extracts at standard doses, it was reported the average intake of turmeric by Asians varies from 0.5-1.5 g/day/person, which produces no toxic symptoms (33). Human clinical trials also indicate that curcumin has no toxicity when administered at doses of 1-8 g/day (34) and $10 \mathrm{~g} /$ day (35). It was also shown that there is no evidence that dietary consumption of turmeric as a spice adversely affects pregnancy or lactation, the safety of curcumin supplements in pregnancy and lactation has not been established.

Conflict of interests: We declare that we have no conflict of interests. 


\section{References}

1. Chattopadhyay I., Biswas K., Bandyopadhyay U., Banerjee R.K. 2004. Turmeric and curcumin: Biological actions and medicinal applications. Review. Current Science, Vol.87 (1), 44-53.

2. Anonymous 2015. Curcuma longa. Alternative Medicine Review Monographs. 119-125.

3. Ruby A.J., Kuttan G., Dinesh B., Rajasekharan K.N., Kuttan R. 1995. Antitumor and antioxidant activity of natura curcuminoids. Cancer Lett., 94, 79-83

4. Basu A., Suresh Kumar G. 2014. Interaction of the dietary pigment curcumin with hemoglobin: energetics of the complexation. Vol 5, Food Funct. 1949-1955.

5. Aggarwal B.B., Kumar A., Bharti A.C. 2003. Anticance Potential of Curcumin: Preclinical and Clinical Studies. Anticancer Research. 23, 363-398

6. Ammon H.P.,Wahl M.A. 1991.Pharmacology of Curcuma longa. Planta Med. 1991,57,1-7.

7. Chan, M.M., Adapala, N.S., Fong, D. 2005. Curcumin overcomes the inhibitory effect of nitric oxide on Leishmania. Parasitol Res. 96, 49-56.

8. Sreejayan S., Rao M.N. 1997.Nitric oxide scavenging by curcuminoids. J. Pharm. Pharmacol. 49, 105-107.

9. Brouet I.; Ohshima H. 1995. Curcumin, an anti-tumou promoter and anti-inflammatory agent, inhibits induction of nitric oxide synthase in activated macrophages. Biochem. Biophys. Res. Commun. 206, 533-540. 5.

10. Dikshit M., Rastogi L., Shukla R., Srimal R.C. 1995 Prevention of ischaemia-induced biochemical changes by curcumin \& quinidine in the cat heart. Indian J. Med. Res. 101, 31-35.

11. Kiso Y., Suzuki Y., Watanabe N., Oshima Y., Hikino H. 1983. Antihepatotoxic principles of Curcuma longa rhizomes. Planta Med. 49, 185-187.

12. Vishwanatha swamy a., Gulliaya s., thippeswamy a., kot b.c., manjula d.v. 2012. cardioprotective effect of curcumin against doxorubicin-induced myocardial toxicity in albino rats. indian j pharmacol. 44(1): 73-77.

13. Srivastava R. Dikshit M., Srimal R.C., Dhawan B.N. 1985 Thrombosis Research, 40(3):413-7

14. Zahidah A.F., Faizah O., Nur Aqilah K., Tatyanna K. 2012 Curcumin as an Anti-Arthritic Agent in Collagen-Induced Arthritic Sprague-Dawley Rats. Sains Malaysiana, 41(5), 591-595

15. Aggarwal B.B., Kumar A., Bharti A.C. 2003. Anticance Potential of Curcumin: Preclinical and Clinical Studies. Review. Anticancer Research, 23, 363-398.

16. López-Lázaro M. 2008. Anticancer and carcinogenic properties of curcumin: considerations for its clinical development as a cancer chemopreventive and chemotherapeutic agent. Mol Nutr Food Res. 52(1), 10327.

17. Sharma O.P. 1976. Antioxidant activity of curcumin and related compounds. Biochem.Pharmacol., 25, 1811-1812.
18. Wright J.S. 2002. Predicting the antioxidant activity of curcumin and curcuminoids. J.Mol Struct., 591, 207-217.

19. Anand P., Thomas S.G., Kunnumakkara A.B., Sundaram C., Harikumar K.B., Sung B., Tharakan S.T., Misra K., Priyadarsini I.K., Rajasekharan K.N., Aggarwal B.B. 2008. Biological activities of curcumin and its analogues (congeners) made by man and mother natüre. Biochemical Pharmacology. 76, 1590-1611.

20. Priyardarsini K.I., Maity D.K., Naik G.H., Kumar M.S., Unnikrishnan M.K., Satav J.G. et.al.. 2003. Role of phenolic $\mathrm{O}-\mathrm{H}$ and methylene hydrogen on the free radical reactions and antioxidant activity of curcumin. Free Radic Biol Med. 35, 475-484.

21. Barclay L.R., Vinqvist M.r., Mukai K., Goto H., Hashimoto Y., Tokunaga A. et.al. 2000. On the antioxidant mechanism of curcumin: classical methods are needed to determine antioxidant mechanism and activity. Org.Lett. 2, 28412843.

22. Jovanovic S.V., Steenken S., Boone C.W., Simic M.G.. 1999. $\mathrm{H}$-atom transfer is a preferred antioxidant mechanism of curcumin. J. Am.Chem. Soc., 121, 9677-9681.

23. Suzuki M., Nakamura T., Iyoki S., Fujiwara A., Watanabe Y., Mohri K. et.al. 2005. Elucidation of anti-allergenic activities of curcumin-related compounds with a special reference to their anti-oxidative activities. Biol Pharm Bull, $28,1438-1443$

24. Chen W.F., Deng S.I., Zhou B., Yang L., Liu Z.I. 2006. Curcumin and its analogues as potent inhibitors of low density lipoprotein oxidation: $\mathrm{H}$-atom abstraction from the phenolic groups and possible involvement of the 4hydroxy-3-methoxyphenyl groups. Free Radic Biol Med., 40, 526-535.

25. Labban L. 2014. Medicinal and pharmacological properties of Turmeric (Curcuma longa): A review. Int J Pharm Biomed Sci, 5(1):17-23.

26. Huang H.C., Jan T.R., Yeh S.F. 1992. Inhibitory effect of curcumin, an anti-inflammatory agent, on vascular smooth muscle cell proliferation. Eur J Pharmacol 221, 381-384.

27. Chen H, Zhang ZS, Zhang YL, Zhou DY. 1999. Curcumin inhibits cell proliferation by interfering with the cell cycle and inducing apoptosis in colon carcinoma cells. Anticancer Res 19, 3675-3680.

28. Martin-Cordero C., Lopez-Lazaro M., Galvez M., Ayuso M.J. 2003. Curcumin as a DNA topoisomerase II poison. J.Enzyme Inhib.Med.Chem., 18, 505-509.

29. Wanninger S., Lorenz V., Subhanb A., Edelmann F.T. 2015. Metal complexes of curcumin- synthetic strategies, structures and medicinal applications. Chem. Soc. Rev., 44, 4986-5002.

30. Ammon HPT, Wahl MA. 1991. Pharmacology of Curcuma longa. Planta Medica 57:1-7.

31. Bhavani Shankar T.N., Shantha N.V., Ramesh H.P., Murthy I.A.S., Murthy V.S. 1980. Toxicity studies on turmeric (Curcuma longa): acute toxicity studies in rats, guinea pigs and monkeys. Indian J. Exp. Biol., 8, 73-75. 
32. Sambaiah K., Ratankumar S., Kamanna V.S., Satyanarayana M.N., Rao M.V.L. 1982. Influence of turmeric and curcumin on growth, blood constituents and serum enzymes in rats. J. Food Sci. Technol., 19, 187-190.

33. Eigner D., Scholz D. 1999. Ferula asa-foetida and Curcuma longa in traditional medicinal treatment and diet in Nepal. J. Ethnopharmacol., 67, 1-6.
34

Chainani-Wu, N. 2003. Safety and antiinflammatory activity of curcumin: a component of turmeric (Curcuma longa). J.Altern.Complement Med., 9, 161-168.

35. Aggarwal B.B., Kumar A., Bharti A.C. 2003. Anticancer potential of curcumin: preclinical and clinical studies. Anticancer Res., 23, 363-398. 